\title{
THE MODERN ROLE OF CONTEXT IN DECISION-MAKING
}

\author{
Y. Chaplinskyy
}

V.M. Glushkov Institute of Cybernetics of NAS of Ukraine

\begin{tabular}{l}
\multicolumn{1}{c}{ Key words: } \\
Decision-support system \\
Decision-making \\
Context \\
Knowledge management \\
\hline
\end{tabular}

Article history:

Received 05.11.2018

Received in revised form

16.11.2018

Accepted 12.12.2018

Corresponding author:

Y. Chaplinskyy

E-mail:

npnuht@ukr.net

\begin{abstract}
Modern decision-making with the use of knowledgebased technologies is seen as a powerful competitive advantage at the enterprise, focused on permanent changes in business processes. The activities of both individuals and systems are increasingly depend on the use of knowledge as one of the most valuable resources. The complexity of implementing such decision-making is the need to synthesize different points of view on the problem, use of terms and concepts from various subject areas, description of own ideas to manage with a large amount of information relevant to the problem, and understanding of the problem decisions etc. Decision-making and integration of the components of decision-making are based on the representation of multilevel governance and decision-making through the context model. The presented approach is aimed at building a context model representing the problem(s) to be solved by the decision support system.

Context describes factors which influence the problem and provides requirements to solutions to be generated for the decision maker. The context in the paper is defined as a collection of objects in which each object has a set of names and relations, and represents a construct consisting of concepts within the context areas and is described by the context ontology. The context ontology takes into account different context areas, such as: purpose/ result, factor, process/action, object, medium, facility, tools, presentation, location, and time. Objects, relationships, and attributes are used to represent contextual domains. Contextual concepts are interconnected through relationships, including intradomain, interdomain and intercontextual relationships. Possible contextual relationships between contextual domains that can be structural (hierarchical) and semantic (associative) are presented.
\end{abstract}

DOI: $10.24263 / 2225-2924-2018-24-6-3$

\section{СУЧАСНА РОЛЬ КОНТЕКСТУ ПРИ ПРИЙНЯТТІ РІШЕНЬ}

\section{Ю.П. Чаплінський}

Інститут кібернетики ім. В.М. Глушкова НАН Украӥни

Прийняття рішень з використанням знання-орієнтованих технологій сьогодні розглядається як потужна конкурентна перевага на підприємстві, 
орієнтованому на постійні зміни ділових прочесів. Діяльність як окремих людей, так і систем зараз все більшою мірою залежить від використання ними знань як одного з найщінніших ресурсів. Складність у реалізації такого прийняттт рімень полягає в необхідності синтезу різних точок зору на проблему, використання термінів і понять з різних предметних галузей, опису свойх ідей управління великою кількістю інформації, що стосується проблеми, та розуміння рішень, щуо приймаються, тощо. Прийняття рішень та інтеграиія складових прийняття рішень базується на представленні багаторівневого управління та прийнятття рімень за допомогою контекстної моделі. Розроблений підхід спрямований на побудову контекстної моделі, що представляє проблему, яку потрібно розв'язати за допомогою системи підтримки прийняття рімень. Контекст описує чинники, щуо впливають на проблему, $і$ забезпечує вимоги до рішень, які необхідно створити для осіб, що приймають рімення.

У статті контекст визначається як сукупність об'єктів, в рамках яких кожен об'єкт має множину імен та відношень, являє конструкцію, що складається з понять у межах відповідних контекстних областей $і$ описується онтологією контексту. У рамках такого розгляду онтологія контексту включає такі контекстні області: мета/результат, фактор, прочес/дія, об'єкт, середовище, можливості, засоби, представлення, розташування та час. Для представлення контекстних областей використовуються класи об'єктів, відношень та атрибутів. Контекстні поняття взаємозв'язані між собою через контекстні відношення, включаючи внутрішньобласні, міжобласні та міжконтекстні відношення. Представлені можливі контекстні відношення між контекстними областями, які можуть бути структурними (ієрархічними) та семантичними (асойіативними).

Ключові слова: система підтримки прийняття рішень, прийняття рішень, контекст, управління знаннями.

Постановка проблеми. Діяльність як окремих людей, так і систем зараз все більшою мірою залежить від використання ними знань як одного 3 найцінніших ресурсів. Сучасні розв'язки прикладних задач $є$ результатом поєднання та інтеграції знань, розуміння та ідей розв'язання множин взаємозв'язаних задач із різних предметних областей, кожна 3 яких має свої специфічні передумови. Складність у реалізації прийняття рішень полягає в необхідності синтезу різних точок зору на проблему, використання термінів і понять 3 різних предметних областей, для опису своїх ідей управління великою кількістю інформації, що стосується проблеми, та розуміння рішень, що приймаються, тощо.

Фундаментальні виклики, що стоять перед прийняттям рішень, виявляються у побудові спільного розуміння поставленого завдання (яке часто не існує зазделегідь, але формулюється поетапно та спільно). При цьому необхідно розуміти відношення між елементами середовища прийняття рішень.

Прийняття якісних рішень відбується як через горизонтальні перехресні вузли, так і через вертикальні перехресні ієрархічні зв'язки, при цьому можли- 
ве отримання раніше недоступної інформації, що в подальшому дає змогу розвивати нові знання та розуміння.

Для цього всі знання, що використовуються, розглядаються в розрізі знань, що описують контекст, та знань, що описують контент.

Контекст $є$ важливим фактором у процесі прийняття рішень, допомагає визначити, яка інформація необхідна для підтримки прийняття рішень і являє собою множину взаємопов'язаних компонентів.

Розгляд використання контексту в проблемних областях допомагає виявити всі семантичні відношення, надати всю необхідну інформацію та правильні інтерпретації для прийняття рішень, оскільки використання інформації в процесі прийняття рішень, як правило, відбувається в контексті складної структури процесу прийняття рішень, який часто формується за допомогою цілого ряду чинників.

Це вимагає створення нових способів отримання та представлення знань про контекст проблеми й віповідного процесу прийняття рішень, взаємодії складових тощо.

Аналіз останніх досліджень і публікацій. Існуючі дослідження щодо контексту використовують різні підходи для визначення контексту та його використання.

У галузі інформаційних технологій контекст вивчався в таких сферах, як знання та різні інформаційні системи для динамічної обробки складних знань [1] або створення інтелектуальних інтерфейсів користувача [2], в яких відбувається цілеспрямована діяльність [2; 3]. В подальшому почали визначати контекст як будь-яку інформацію, яка може зафіксувати ситуацію. В [4] розглянуто декілька сотень праць та запропонована модель контексту, що містить компоненти користувач, об'єкт, спостерігач і навколишнє середовище та різні відношення між цими компонентами. В [3] визначено, що контекст розглядається як представлення проблеми, беручи до уваги такі властивості контексту [3; 5]:

- контекст - це форма інформації, тобто контекст розглядається як те, що може бути відоме, представлене та закодоване;

- контекст $є$ вичерпним, тобто вважається можливим визначити, що заздалегідь визначається як контекст для конкретного використання;

- контекст є стабільним, тобто коли контекст може відрізнятися від застосування до програми, він не відрізняється від екземпляра до примірника взаємодії з додатком;

- контекст і діяльність є розділеними, тобто контекст використовується для опису особливостей середовища, в межах якого здійснюється діяльність, але елементи діяльності не відносяться до самого контексту та не розглядаються як контексти.

Проте не існує загальновизнаного визначення контексту у сферах, пов'язаних з прийняттям рішення.

У [6] представлено три класи контекстних моделей, що базуються на застосуванні, моделях та онтології. Так, модельні підходи побудовані на основі концептуалізації області прийняття рішень, що використовує стандартні репрезентативні структури (наприклад, об’єктно-рольові моделі (ORM), уніфі- 
ковану модельну мову (UML) та моделі сутностей-відносин (ER моделі)). Останній клас контекстних моделей грунтується на представленнях знань, що формалізовані в онтологіях.

Під онтологією будемо розуміти систему, що описує структуру певної проблемної області або множини проблемних областей та складається з множини класів понять, зв'язаних відношеннями, їх визначень та аксіом, що задають обмеження на інтерпретацію цих понять в рамках певної проблемної області або ïx множини [7]. Мета такої онтології полягає в тому, щоб забезпечити інтегровану концептуальну основу. Це дасть змогу визначити, зрозуміти, структурувати та представляти явища при прийнятті рішень за допомоги СППР.

Проте рішення щодо того, яка інформація необхідна для розв'язання задачі, в цих підходах повинно бути визначене на етапі формулювання проблеми та процесу прийняття рішень. Окрім того, мало уваги приділялося динамічним аспектам контексту.

Мета дослідження: аналіз сучасного використання контексту для інтегрованого структурованого представлення складових прийняття рішень, їх взаємодії та реалізації знаннє-орієнтованого прийняття рішень.

Викладення основних результатів дослідження. Під підтримкою прийняття рішень слід розуміти інтелектуальну комп'ютерну технологію посилення можливостей людини, що приймає рішення (ЛПР) в процесі спостереження за станом проблемної області, діагностики проблемних ситуацій і цілей дій, планування дій і генерацію способів їх реалізації, формування раціональних варіантів рішень з використанням експертних знань і методів моделювання та оптимізації. Область прийняття рішень будемо розглядати як багаторівневу структуру, що включає область проблем, область моделей, область методу та область реалізацій. Область прийняття рішень можна декомпозувати на елементарні об'єкти, кожен 3 яких описується сукупністю атрибутів. В рамках такого розгляду необхідно визначити поняття та конструкції, за якими можуть бути визначені природа, структура та представлення процесу формування та прийняття рішень і відповідних складових областей, що описують такий процес.

Базуючись на цьому, реалізація процесів прийняття рішень звертається до осіб, організаційних одиниць, посад, ролей, задач, ресурсів, об'єктів та їх відношень відповідним чином. Реалізація процесів прийняття рішень та інтеграція складових прийняття рішень, у свою чергу, базується на представленні багаторівневої системи управління та прийняття рішення в ній через модель певного контексту.

Слід зауважити, що, по-перше, контекст є невід'ємною властивістю випадків взаємодії, а не є стабільним об'єктивним набором функцій, які зовнішньо характеризують діяльність. Контекст залишається критично важливим для розуміння, контекстуалізації та непорозуміння форм діяльності та інформації, але саме в контексті природи необхідно постійно домовлятися та переглянути його. По-друге, ці контекстні властивості беруть на себе їх значення або релевантність через їхній зв'язок з формами практики, тобто діями навколо артефактів та інформації, яка робить ці артефакти значущими й актуальними 
для людей. Тоді сенс технології не може бути відірваний від способів використання його людьми.

При цьому контекстна модель повинна охоплювати компоненти відповідних об'єктів. Основними компонентами такої моделі є: елемент, користувач, спостерігач, середовище та інші контексти, пов'язані з ними. Контекст повинен охоплювати принаймні частини цих компонентів.

Тож контекст можна охарактеризувати так: виникає через простір і час; причинно-наслідковий процес прийняття рішень; визначений, але не обов'язково передбачуваний; семантична інтерпретація відносин між актором, завданням або діяльністю та середовищем, в яких вони знаходяться; обмежувальні критерії, за допомогою яких можна моделювати цілеспрямовану діяльність.

Під контекстом будемо розуміти будь-яку інформацію, яка може бути використана або характеризує відповідну складову процесу розв'язання проблемних задач. Наше представлення контексту складається зі змісту, що базується на онтологіях, які охоплюють певну частину моделі контексту.

Такий погляд використовує іншу позицію по кожному з чотирьох перерахованих вище припущень: по-перше, замість того, щоб розглядати контекст як інформацію, можна стверджувати, що контекстуальність $є$ реляційною властивістю, яка визначається між об'єктами або діями. Це не просто те, що щось $\epsilon$ або не є контекстом; Навпаки, вона може або не може бути контекстуально актуальною для певної діяльності. По-друге, можна стверджувати, що обсяг контекстних функцій визначається динамічно. По-третє, можна стверджувати, що контекст $є$ особливим для кожного випадку діяльності або дії. Контекст - це властивість, пов'язана з певними налаштуваннями, окремими випадками дії та особами, що беруть участь у цій дії. По-четверте, , щоб контекст та вміст стали двома відокремленими об'єктами, він замість цього стверджує, що контекст виникає в результаті діяльності. Іншими словами, те, що я хочу зробити тут, полягає в тому, щоб переглянути контекст не як проблему представлення, а як проблему взаємодії.

Модель контексту передбачає суб' єктивний погляд на розв'язання певної ситуації. На відміну від існуючих підходів, де контекст описується в монолітному сенсі або як певна ситуація, необхідно вважати, що будь-який вибір контекстних параметрів та їх питома вага в описі ситуації повинні бути предметом практики.

Оскільки контекстні моделі - це представлення про динамічні умови та відношення, вони базуються на даних, що отримані з різних джерел з різнорідними часовими, тематичними та просторовими якостями.

Контекстні моделі мають вирішувати такі проблеми 3 даними, що використовуються для визначення контекстно-обгрунтованих ситуацій:

- неоднорідність та мобільність;

- відносини та залежності;

- своєчасність;

- недосконалість;

- міркування;

- відповідність формалізму прийняття рішень;

- ефективне контекстне забезпечення. 
Обмеження контексту має важливе значення, інакше проблема створення контекстної моделі буде незрозумілою. Обмеження контексту також зменшує складність часу обчислення потенційних рішень для діяльності. Ми використовуємо такі обмежувальні критерії: наявність даних - наявність або відсутність; повнота; набори включення / виключення; часові межі; просторові межі; область діяльності.

Контекст розглядається як динамічні відношення між актором, цілеспрямованим завданням та оточенням, в яких вони знаходяться. Такий розгляд дає змогу контекстним зв'язкам виникати, змінюватися або зникати через час і простір та охоплювати складність просторово-часової динаміки. Ми застосовуємо таке представлення контексту, оскільки воно забезпечує моделювання контекстної динаміки, що виникає в процесі розв'язання задачі, а не тільки вибирається на етапі формулювання проблеми та процесу розв'язання задачі.

Практика являє собою повторюваний візерунок, який можна заповнити різними заходами, і позначає контекстуальні характеристики набору заходів, включаючи форму діяльності, модель взаємодії, інструменти та їх використання, а також деякі форми знання.

Модель контексту передбачає суб'єктивний погляд на проблемні рішення ситуації. На відміну від існуючих підходів, де контекст описується в монолітному сенсі або як певна ситуація, ми вважаємо, що будь-який вибір контекстних параметрів і їхня питома вага в описі ситуації повинні бути предметом переважаючих практики. Отже, ми моделюємо контекст 3 практичної точки зору та представляємо структуру контексту, яка успадковується від традиційних моделей контексту [2; 3].

Тож контекст можна розглядати як будь-яку інформація, яка може бути використана для опису ситуації, в якій щось існує чи відбувається, та яка може допомогти пояснити ситуацію. Ця ситуація залежить від знань, світогляду, практики та обставин, які можуть бути використані для побудови «нескінченної і частково відомої сукупності припущень» [8], що утворюють інтегральне рішення проблем підходи організації або групи осіб, і які забезпечують для і всередині організації або групи схеми для створення, підтримки та застосування знань.

При цьому різні контексти можна формалізувати та інтегрувати в множину різнорідних об'єктів, застосовучи правила мосту (через певні відношення). Контекстна модель відображає міркування з частковим знанням.

Така контекстна модель може бути використана як допомога для моделювання контексту для прийняття рішень. Проте для досягнення трьох функцій контексту, тобто синтаксису, семантичної та прагматичної функції, потрібно розглянути питання про предствлення цих компонентів семантично та прагматично.

Базуючись на цьому, будемо розглядати контекст як концептуальну або інтелектуальну конструкцію, яка складається з понять в межах відповідних контекстних областей та допомогає нам зрозуміти, проаналізувати й використовувати природу, значення та ефекти через елементарні сутності у відпо- 
відному середовищі або обставинах. Також контекст представляє ціле, що визначається через певні сутності, які є важливими при такому розгляді.

Об'єкт може бути пов'язаним з іншим контекстом, що ми називаємо посиланням. Імена та посилання $є$ контекстно-залежними.

Контекст складається з ідентифікатора контексту $C$ та множини ідентифікаторів об'єктів, які позначаються $\operatorname{Objs}(C)$, так що кожне $O \in \operatorname{Objs}(C)$ пов'язане 3 :

1. Множиною імен, які називаються іменами $O$ в $C$, і позначається іменами $(O, C)$.

2. Більш одного контекстного ідентифікатора, що називається посиланням або відношенням $O$ в $C$, і позначається $\operatorname{ref}(O, C)$.

Якщо $O \in O \operatorname{Objs}(C)$ не пов'язане $з$ контекстом ідентифікатора, то посилання $\operatorname{ref}(O, C)$ вважається невизначеним.

Формально будемо розглядатати контекст як конструкцію, що складається 3 понять у межах відповідних контекстних областей та описується онтологією контексту через таку структуру контекстних областей [9]:

$$
O_{c t x}=\left\langle O_{c t x}^{A R}, O_{c t x}^{A}, O_{c t x}^{P A}, O_{c t x}^{O}, O_{c t x}^{E}, O_{c t x}^{F}, O_{c t x}^{F c l t}, O_{c t x}^{R}, O_{c t x}^{P l c}, O_{c t x}^{T}\right\rangle .
$$

На загальному рівні $O_{c t x}$ описується такими контекстними областями: $O_{c t x}^{A R}$ - мета/результат, $O_{c t x}^{A}$ - актор, $O_{c t x}^{P A}$ - процес/дія, $O_{c t x}^{O}$ - об'єкт, $O_{c t x}^{E}-$ середовище, $O_{c t x}^{F}$ - можливості, $O_{c t x}^{F c l t}-$ засоби, $O_{c t x}^{R}-$ представлення, $O_{c t x}^{P l c}$ - розташування, $O_{c t x}^{T}$ — час.

Так, $O_{c t x}^{A R}$ складається 3 понять та конструкцій, які відносяться прямо або побічно до цілей, спонукань або намірів, бажаних результатів чогось або певної сутності. $O_{c t x}^{A}$ складається 3 понять та конструкцій, які звертаються до окремої людини, групи, посади або організаційної системи, соціальної системи, технічної системи, програмного забезпечення. $O_{c t x}^{P A}$ складається 3 понять та конструкцій, які звертаються до процесів, умов, функцій, операцій, задач тощо в контексті. $O_{c t x}^{O}$ складається 3 понять та конструкцій, які звертаються до чогось, для чого призначена або на що спрямована дія. $O_{c t x}^{E}$ складається 3 понять та конструкцій, які представляють, де та в яких умовах відбувається щось. $O_{c t x}^{F}$ складається з понять та конструкцій, які представляють, що і де ми можемо використати. $O_{c t x}^{F c l t}$ складається з понять та конструкцій, які визначають, як щось може бути застосоване або зроблене та що може бути вирористане. $O_{c t x}^{R}$ складається з понять та конструкцій, які відносяться до форми представлення чогось. $O_{c t x}^{P l c}$ складається з понять та конструкцій, які звертаються до частини місця, зайнятого кимось або чимось. $O_{c t x}^{T}$ складається 3 понять та конструкцій, які звертаються до часових аспектів у контексті. 
Для представлення контекстних областей будемо використовувати класи об’єктів, відношень та атрибутів, що дає можливість представляти їх як семантичні аспекти, де семантика умов і відношень між ними визначені явним чином (таким чином роблячи кожен аспект формальною онтологією). Використання таких категорій дає змогу зробити формалізацію аспектів в логіці опису (дескрипційна логіка) (DL).

Контекстні поняття взаємозв'язані між собою через контекстні відношення, включаючи внутрішньобласні, міжобласні та міжконтекстні відношення, тобто такі відношення включають не тільки відношення між компонентами однієї області, а й відношення між іншими контекстами. Такі поняття та конструкції необхідні для того, щоб визначити, зрозуміти, структурувати та представити сутності як контексти та/або в межах контекстів, щоб зрозуміти природу, цілі та значення відповідних сутностей задач та процесу прийняття рішень.

Відношення будемо поділяти на структурні (ієрархічні) та семантичні (асоціативні). До структурних відношень будемо відносити такі відношення: класифікація, конкретизація, узагальнення, спеціалізація, відношення akindOf, агрегація, декомпозиція, групування, індивідуалізація, відношення омонімії. Асоціативні відношення дають змогу зрозуміти, в якому зв’язку перебувають поняття, що описують один клас онтології, з поняттями іншого класу. На рівні контекстних областей існують структурні та семантичні відношення. Наприклад, в області мета/результат існують відношення агрегації (частинаціле), тобто ціль може мати підцілі. В цій же області можуть виникати асоціативні відношення між проблемами, наприклад, відношення причинності, коли виникнення однієї проблеми є причиною виникнення інших проблем. В області процес/дія виникають відношення управління - послідовність, ітерація, вибір, заміщення, заборони, аддитивності. В області часу є множина часових відносин, які можуть бути визначені для часових точок та інтервалів часу.

Описане представлення контексту дає змогу: 1) логічно виводити новий контекст 3 наявних; 2) повторно використовувати контекст за допомогою застосування контекстів вищих рівнів абстракції, їх інтеграції та конкретизації для відповідних умов і завдань; 3) отримувати контекст більш високого рівня абстракції з розглянутого контексту; 4) розбивати контекст на складові його логічно пов'язані внутрішньо узгоджені контексти.

Орієнтація систем підтримки прийняття рішень на використання контексту дає змогу, не впливаючи безпосередньо на процес прийняття рішень, обмежити його лише значущими для цього контексту правилами/процедурами. Тож $з$ точки зору систем підтримки прийняття рішень контекст забезпечує більш ефективне використання ресурсів середовища, в якому функціонує система. 3 точки зору користувача контекст надає йому дійсну, релевантну і доступну для вирішення його завдання інформацію. Контекст прийняття рішень дасть нам можливість визначення потенціалу та меж для підтримки прийняття рішень, при цьому він забезпечить умови, які формують процеси прийняття рішень. 


\section{Висновок}

Представлений підхід до опису контексту та використання його для розв'язання задач прийняття рішень дає змогу реалізувати інтелектуальну підтримки прийняття рішень в динамічних структурованих областях, основою якої $\epsilon$ контекст та онтологія. Запропонований підхід був покладений в основу інформаційної системи, що реалізована як складова частина вірмено-американського проекту з технічної допомоги в галузі безпеки продуктів харчування.

\section{Лiтература}

1. Giunchiglia F., Dutta B., Maltese V., Farazi F. A facet-based methodology for the construction of a large-scale geospatial ontology. Journal on Data Semantics, 2012. 1. P. 57-73.

2. Dey A.K., Salber D., Abowd G.D. A Conceptual Framework and a Toolkit for Supporting the Rapid Prototyping of Context Aware Applications. Human-Computer Interaction (HCI) Journal, 2001. 16. P. 97-166.

3. Dourish P. What we talk about when we talk about context. Personal and ubiquitous computing, 2004. 8. P. 19-30.

4. Bazire M., Brézillon P. Understanding Context Before Using it / In: Dey, A. et al. (eds.) CONTEXT 2005, LNAI 3554. Berlin Heidelberg: Springer-Verlag, 2005. P. $29-40$.

5. A survey of context modelling and reasoning techniques / C. Bettini, O. Brdiczka, K. Henricksen, J. Indulska, D. Nicklas, A. Ranganathan, D. Riboni. Pervasive and Mobile Computing, 2010. 6. P. 161-180.

6. Gu T., Wang X.H., Pung H.K., Zhang D.Q. An ontology-based context model in intelligent environments. In Proceedings of communication networks and distributed systems modeling and simulation conference, 2004. P. 270-275.

7. Чаплінський Ю.П. Онтологічне представлення процесів прийняття рішень. Проблеми інформатизаиї̈ та управління, 2009. № 2(26). С. 146-151.

8. Porzel R. Contextual Computing: Models and Applications. (Cognitive Technologie s). Springer Verlag, 2010. $180 \mathrm{p}$.

9. Чаплінський Ю.П., Субботіна О.В. Онтологія та контекст при розв'язанні прикладних задач прийняття рішень. Штучний інтелект, 2016. № 2. С. 147-155. 